\title{
E-Tailing in Kosovo: The Effect of Trust, Satisfaction and Service Quality in Achieving Consumer E-Loyalty
}

\author{
MSc. Fehmi Azemi \\ PHD Candidate in the Faculty of Economy and Agribusiness (Agricultural University Tirana) \\ Dr. Fiqiri Baholli \\ Professor in the Faculty of Economy and Agribusiness (AU Tirana) Email: fbaholli@yahoo.com \\ Dr. Elton Guberaj \\ Professor in the Faculty of Economy and Agribusiness (AU Tirana) Email: egubera@ubt.edu.al
}

\section{Doi:10.5901/ajis.2015.v4n3s1p502}

\section{Abstract}

\begin{abstract}
The global e-tailing industry growth in numbers of online consumers has been impressivein recent years. Because of the low entry barriers, this trend is equally evident in the number of providers. Online consumer behaviour has attracted the attention of researchers to investigate this phenomenon, who have identified e-loyalty as the most important source ofbusiness stability and profitability. Among various perspectives, the elements of trust, satisfaction, and service quality have been proposed as originators of e-loyalty. Yet, previous efforts fail to consider the combined effect of these factors, and largely ignore the occurrence of this phenomenon in developing countries. This research deducts the extant theories to develop and empirically test the hypotheses by employing a closed-ended online questionnaire. The findings show a significant positive correlation between the proposed relationships from the perspective of Kosovo online consumers, towards Kosovo e-tailers. The conclusions are drawn and future research directions are identified.
\end{abstract}

Keywords: Trust, Satisfaction, Service Quality, Website Customisation, E-loyalty, E-tailing, E-Commerce.

\section{Introduction}

Today's online consumers have become more demanding than ever, since they have access to sufficient information; they have lower switching costs; greater number of alternatives; and they are constantly one click away from making a purchase decision. This indicates that predicting and controlling consumer behaviour has become difficult (Amani, 2015). It has been recently reported that the number of online consumers is increasing at extensive rates, with an average growth of around $20 \%$ on a global basis (Subramanian et al., 2014). Indeed, this growth is being noticed on all levels of etail categories, ranging from virtual book stores, online groceries, apparel, electronics, and many more (Chen et al., 2012).

In contrast with traditional brick and mortar stores, the Internet environment is significantly complex, particularly in terms of alternative and competing offers. Low entry barriers of the online retailing industry and the sophistication of digital marketing technologies are placing e-tailers under great pressure (Wu and Tseng, 2015).Researchers have noted that online businesses have been rather naïve in the early stages of doing business online. E-tailers have been wrongly focusing only on acquiring new consumers while struggling to recognise the advantages attached to satisfying and retaining the existing ones. To make matters worse, online consumers have indicated different attitudes and shown signs of dissimilar behaviour compared to the traditional expectations. This has grown the e-tailers confusion, thus it has attracted the attention of scholars to explore this phenomenon. To this effect, commercial transactions between consumers and e-tailers are no longer approached with the traditional focus on acquisition. Conversely, greater emphasis is currently placed on retaining existing consumers (Ozuem et al., 2015).

Increasing the efforts to retain existing online consumers is a logical resolution, considering the probability of greater benefits that e-tailers have to achieve stability and profitability (Rafiq et al., 2013). Moreover, recent findings assert that e-tailers have the chance to elevate their profits up to $125 \%$ by employing strategies that focus on retaining 
their online consumers (Srivastava and Rai, 2014).

Various investigations have been conducted in this domain and previous researchers have developed theories that suggest several originators of loyalty in an online context. Extant literature is fragmented into several perspectives regarding the development of e-loyalty as the main goal of relationship marketing. Kim et al. (2009) suggest that both satisfaction and trust are vital inducers of e-loyalty. Kwon and Lennon (2009) note that online consumers' perceived risk towards an Internet transaction with the e-tailer affects the development of e-loyalty; Fang et al. (2014) propose a positive impact of previous purchase experience in developing e-loyalty; while Zhang et al. (2011) identify website quality and website customization as a strong component in influencing online consumers' trust in an e-tailer and online consumers' repurchase intention.

However, only few descriptive studies have been conducted in this topic (Pizzutti and Fernandes, 2010), and previous studies fail to provide satisfactory outcomes regarding the role of these elements and their effect in an e-tail environment in developing countries, and to the researchers knowledge, there have been no prior investigations conducted in small developing countries such as Kosovo.

WTO (World Trade Organization) reports that developing countries are in a favourable situation to benefit from technological advancements introduced in today's global economy, while emphasising the opportunities that have arisen in particular industries such as e-commerce and e-tail (World Trade Organisation, 2013). Pizzutti and Fernandes (2010) suggest that there is a correlation between high levels of Internet access and Internet penetration in one side, and the development of online retailing on the other side.

Kosovo is a Southeast European country with a population of around 1.8 million people (Kosovo Agency of Statistics, 2013). Statistical figures reveal Internet penetration of $76.6 \%$ based on users, and $84.8 \%$ based on households (Kosovo Ministry of Foreign Affairs, 2015). These figures are very similar to the data of UK Internet penetration statistics, which is the leading country of online shoppers, where that $87 \%$ of adults have used Internet in the first quarter of 2014 (Office for National Statistics, 2014). The online retail market accounts for $15.2 \%$ of the retail industry, and an average UK consumer is expected to spend $£ 1,174$ online in 2015 (Moth, 2015). Regrettably, there is no data available to the researchers knowledge, which unveils online shopping statistics in Kosovo.

However, based on a research conducted by STIKK (2013) when the respondents were asked about their confidence to shop online, 27.78\% responded "Yes, without doubt"; $7.683 \%$ responded "Yes, if shopping on international well-known websites"; $8.511 \%$ responded "Yes, if there were truthful websites in Kosovo"; $41.37 \%$ responded "Would not believe on online shopping"; and 14.66\% responded "Do not know, never heard of such option". These figuresprovide a clear indication of the requisite to explore this phenomenon in depth.

Consequently, the objective of this research is tounderstand why e-loyalty is relevant for Kosovo e-tailers' business success, andwhat is the effect trust, satisfaction and service quality to e-loyalty, from the perspective of Kosovo online consumers.

\section{Theoretical Background}

The growth of Internet penetration on a global scale has reshaped the way in which companies do business. Business-toconsumer (B2C) firms have established their online presence as an attempt to acquire new consumers and retain the existing ones for long-term profitability. E-loyalty is a relatively new concept that broadens the definition of traditional loyalty to adapt consumer behaviour in an online environment (Carter et al., 2014). In absence of physical human interactivity revolved around this environment, traditional loyalty literature has adjusted its definitions accordingly. Yao et al. (2015) defines e-loyalty as the consumer's intention to use a website and to take into consideration placing an order from that website in the future. Other definitions portray e-loyalty as a consequence of a positive intention of a consumer that manifests commitment towards an online business that results in repeated purchase behaviour (Asgari, 2014).For the purpose of this study, the researchers have chosen to identify the measures of loyalty, in order to conceptualise this phenomenon in an online context. Therefore, three major approaches were identified in consumer loyalty measures that were proposed by scholars, i.e. attitudinal measures, behavioural measures, and cognitive measures.

An attitudinal point of view reflects consumer loyalty as a deep commitment to repurchase a favourite product or service in the future, without being affected by competitive efforts that generate switching behaviour (Moreira and Silva, 2015). However, applying only an attitudinal construct to measure the consumers' psychological and emotional bond towards the provider has been criticized in the literature (Al-hawari, 2015). Moreover, the researcher suggests that emotional attachment fails to always materialise into action.

The cognitive approach, as suggested by Lopez-Mosquera and Sanchez (2014), portrays the creation of 
judgements and beliefs, where consumer satisfaction is regarded as an outcome of the consumer's perceived results and their expectations. This implies an attitudinal construct; therefore the researchers consider that cognitive loyalty can be categorized as attitudinal loyalty together with emotional and psychological loyalty.

Conversely, a measurement that focuses exclusively on behavioural characteristics limits the definition of loyalty as repeated transactions or returning consumers, which is measured by simple observations (Jumaev, 2012). Yet, behavioural loyalty can be considered as crucial from the managerial perspective, since it is translated into actual sales and revenues for the e-tailer. However, it is suggested that behavioural loyalty bears higher costs for the e-tailer and requires considerable commitment by the consumer (Liao et al., 2014).

There is no universal agreement between scholars regarding the dimensions of consumer loyalty and their measurement, yet the combination of behavioural and attitudinal loyalty is supported as a consensus between contemporary social scientists (Han and Woods, 2014). Based on this construct, the researcher proposes to include consumer trust and previous purchase satisfaction a composite measurement of e-loyalty for the purpose of this research.

However, there is another perspective of conceptualising consumer loyalty in regards to service quality (Zeithaml et al., 2013). This view holds that service quality is an important antecedent of consumer loyalty, and its mediating effect has been explored and empirically tested by previous researchers. Yet, the case differs in an online environment and virtual stores. Various exploratory and empirical studies have been conducted in this aspect, however the research conducted by Hsieh and Tsao (2014) stands out, since it focuses on the perspective of website quality.

The literature considers website quality based on various components, such as Information systems (IS) approach, a marketing oriented approach, or a combination of both (Elkhani et al., 2014). In that context, Hsieh and Tsao (2014) established a conceptual model based on the suggestions of an e-Commerce Success Model proposed by DeLone and McLean (2004). Their empirical test findings reveal that website quality reduces the online consumers' perceived risk which results in e-loyalty. Yet, this study fails to recognise two main elements, the combined role of website quality, trust and satisfaction, and their combined effect on e-loyalty; and the cultural factors that might affect this relationship. The latter is particularly significant for the e-tailers operating in developing countries where this research is conducted, since these business environments are in fact largely influenced by local cultural traditions.

Thus, for the purpose of this study, only website customization is taken in consideration as an originator of eloyalty, based on local cultural preferences such as language and layout.

\subsection{Why is consumer e-loyalty important for the e-tailer?}

Most of the previous researchersargue,based on a study conducted by Harris and Goode (2004), claiming that online consumer loyalty is much more difficult to be achieved, yet it has greater value compared to traditional loyalty (Rafiq et al., 2013). This suggestion is rather disputable when alternative findings are considered. As illustrated by a Harvard Business Review research conducted by Reichheld and Schefter (2000) who set out to examine the strategies of the leading e-tailers by interrogating thousands of their online consumers, they arrive to variant conclusions. In contrast, they note that online consumers are predominantly willing to become loyal towards the e-tailers.

However, there are strong justifications to support the claim that consumer loyalty has greater value for online retailers in comparison to traditional offline stores. Recent studies reinforce this suggestion (Fuentes-Blasco et al., 2010) by implying that online consumer acquisition cost is higher. Moreover, e-tailers need to establish a loyal clientele in order to become profitable, and what is more, the profit volume expands further with time, which gives the e-tailers the prospect to build upon this opportunity by extending their offerings range, i.e. to increase their profits even further.

As a factor worth considering, by returning to the starting point, the findings of Reichheld and Schefter (2000) illustrate that the e-tailers profit value per consumer increases in a considerable amount in a life-cycle of three years, where specific sectors of online stores (i.e. apparel and groceries) almost double within this period.

\subsection{Trust and E-loyalty}

Online shopping involves risk-taking actions from a consumer; therefore trust is needed to build confidence so that Internet transactions can be accomplished. The literature defines trust from various perspectives over several disciplines, i.e. sociology, economics, and social psychology. Furthermore, trust interpretation has been refined in other fields of study such as management, IT systems, and marketing. Pertaining to the marketing domain, trust was approached from a relationship marketing perspective associated with buyer-seller trade, or consumer-company exchange (Chen et al., 
2012).

In that context, scholars suggest that trust at its core is related to an individual's confidence and the will shown by that individual to become vulnerable in an exchange transaction with the other party (Chen and Saeedi, 2006). Another view describes trust as a belief, which is the assumed probability that the other party will act in accordance to the individual's benefit (Sapienza et al., 2013). Yet, it is arguable that beliefs lead inevitably to future intentions, therefore they are not sufficient to justify the existence of trust in regards to e-loyalty (Schlosse et al., 2006). In a less sophisticated proposition, trust is articulated as a person's reliance to another, by risking to become exposed to harm (Hurwitz, 2013). These suggestions emphasise risk as a problem in a personal level, thus trust is further suggested as a resolution to the problem of risk (Vos et al., 2014).

Literature review displays enormous evidence of the positive influence of consumer trust in an e-tailer in developing e-loyalty. Yet, there is another group of researchers that suggest that the role of trust has been exaggerated, whence e-loyalty is not all about trust, it is also about price. In this fashion Valvi and West (2013) research findings suggest that 'trust does not play a pivotal role' (p.2012) in achieving online consumer loyalty. This claim is in contradiction with several theories supported by other researchers. As noted by Lim (2015), consumer trust is the main booster of favourable future intentions for the e-tailer. Bart et al. (2005) findings reveal that consumer trust on an e-tailers website has a positive influence on their eagerness to recommend the e-tailer to their friends and family. Moreover, Moreira and Silva (2015) findings validate the positive effect of trust in developing e-loyalty.

Based on these arguments, for the purpose of this research, the following hypotheses are proposed:

$\mathrm{H} 1$ : Consumer trust in a Kosovo e-tailer has a positive effect on e-loyalty for the e-tailer.

\subsection{Satisfaction and E-loyalty}

Relationship marketing research has been largely focusing on the phenomenon of satisfaction and its outcomes (Gounaris et al., 2010). However, satisfaction has been widely drawn in terms of emotional conditions emerging from the fulfilment of expectations in the possession or consumption experience. Yet, current research studies suggest that this transaction-based conception built only upon a cognitive perspective is not sufficient to understand how satisfaction is generated (Ltifi and Gharbi, 2012). With a similar approach, Flint et al. (2011) imply that relationships between suppliers and consumers reflect deeper connections. Meeting the consumer expectations requires a better understanding of what consumers value, and how their perceptions are built. Moreover, their survey studies show the benefits that suppliers get by recognizing their consumer's perceived value, which results in higher satisfaction and loyalty.

Chen (2012) posits that consumer satisfaction is instrumental in developing e-loyalty. This claim is supported by empirical findings where trust, commitment, involvement, and perceived value are situated as mediators between satisfaction and the formation of e-loyalty. Ludin and Cheng (2014) suggest a view that compares consumer expectations with consumer experience. This view holds that satisfaction is generated when the experience meets or surpasses consumers' expectations. Moreover, satisfied consumers are expected to develop repurchase intentions if the provider has accomplished or surpassed their expectations. Similarly, previous researchers suggest that satisfaction is not onedimensional; it is rather a combination of various elements such as consumer expectations and perceived values (Razavi et al., 2012). However, Deng et al. (2010) argue that the conceptualisation of e-satisfaction should be narrowed to transaction-specific boundaries; otherwise the conceptual context would become over-extensive. Still, the majority of research findings propose that e-satisfaction is a central originator of e-loyalty (Ghane et al., 2011).

Based on these considerations, the researchers hypothesize:

H2: Consumer e-satisfaction has a positive influence on developing e-loyalty for the Kosovo e-tailers.

\subsection{E-service Quality, Website Customization, and E-loyalty}

Traditional service quality literature indicates a connection with cultural perceptions in relation to consumer behaviour. Cultural factors influence consumer expectations, thus they affect their purchase decisions (Kueh and Von, 2007).

In order to further examine this subject, it is significant to understand what constitutes culture and cultural factors. Leung et al. (2005) defines culture as a set of norms, values, beliefs, and behavioural patterns held by a group of people. Other scholars suggest that culture is a simple shared system of meanings. However, the focus of this research lies in an online exchange relationship environment, hence the researchers propose to review cultural factors in regards to eservices quality. In that context, Al-Nasser et al. (2015) propose a combined model of traditional services quality dimensions situated within a web-based service quality. 
Lu et al. (2013) expand this view in regard to the relationship between website quality and the development of online consumer loyalty. They propose to explore e-loyalty with respect to cultural factors, by classifying them as individualism and collectivism. These two concepts that originated from sociology are associated with interdependence of human beings (collectivism) and social independence (individualism). Their findings show that cultural factors indeed have an impact on consumer e-loyalty.

Built upon this theoretical foundation, this study draws a boundary on the view of service quality by taking into consideration only the element of website customization based on local cultural elements such as language, and layout. This approach is further supported by the work of Zhang et al. (2011) and Cyr et al. (2008). The latter propose that online consumers prefer to shop online and exhibit a tendency to become loyal to e-tailers that have customized their websites based on local cultural preferences in comparison to foreign websites (Cyr et al., 2008). Therefore, the following hypothesisis proposed:

H3: Kosovo e-tailer's website customization based on cultural preferences such as language and layout has a positive impact on obtaining consumer e-loyalty.

\section{Conceprual Framework}

The theoretical foundation on which this research is based is deducted into a framework that emphasises the main elements that contribute to resolve the research problem, as illustrated in the figure no.1.

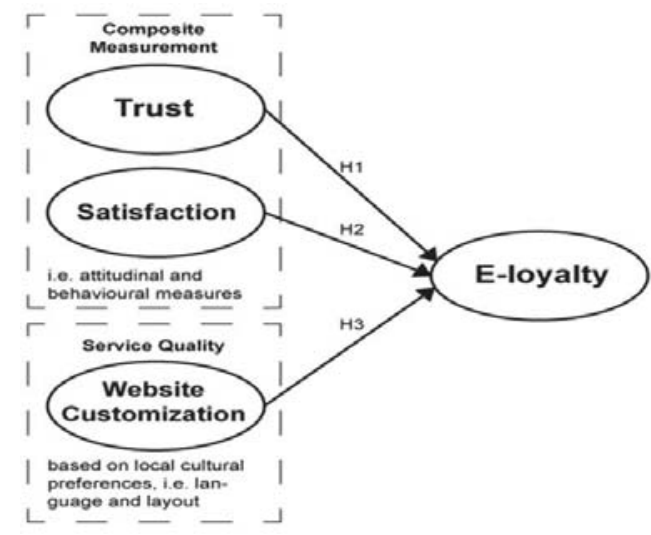

Figure 1. Conceptual Framework

\section{Methodology}

In order to investigate the effect of trust, satisfaction, and service quality on the development of e-loyalty, from a Kosovo online consumers' perspective towards Kosovo e-tailers, an online survey was administered. The researchers took a positivist philosophical standing in order to avoid bias and become objective. The questions were developed from deducting the identified theories by employing a deductive approach; hence the hypotheses were transformed into questions in order to find out the correlation between the variables. The sample was determined using a purposive judgemental sampling method with a preliminary quota in order to avoid error, and to support the validity and reliability of the findings. First, he questionnaire was pilot tested to warrant the effective performance of the questions, and to confirm that the overall research mechanism functions properly.

A purposive sampling technique is a non-probability sampling method that complies with a certain criteria (Babbie, 2015). The researchers designed the questionnaire to query if the respondents had previous purchase experience from Kosovo e-tailers. The respondents that answer negatively this question are not taken into consideration and their data is not included in the analysis of the findings. The respondents were targeted through posts on specialised technology groups in social networks. Additionally, the researchers received support from some Kosovo e-tailers who provided a number of e-mail contacts from their databases in order to construct a sampling frame.

The researchers produced two different collectors to be able to distinguish the origin of respondents, i.e. the 
number of respondents attracted by the social media campaign, and by the e-mail marketing campaign. 209 invitations were sent by e-mail using the YMPL email marketing software, which produced a number of 32 respondents, or 15.3\% within one week. This return rate is lower than the average, as suggested by Fisher (2010), a rate of $30 \%$ is realistic. The social media campaign produced an additional number of 83 respondents. However, 8 responses were missing data on some questions of the online survey, thus the researcher processed only 107 responses. This number was additionally reduced based on the negative answers from the filtering quota, as suggested by Blumberg et al. (2014). Finally, the researchers were left with a total number of 84 responses for the data analysis.

\section{5. $\quad$ Findings}

Based on the quantitative data collection method, i.e. online survey closed-ended questionnaire, which was discussed in the previous section, a descriptive statistics method is used to analyse the demographic characteristics. Moreover, Spearman's correlation technique is utilized to measure the relationship between independent variables and the dependent variable based on the conceptual framework, which indicates that the hypotheses are tested and the findings are evaluated.

Out of 84 respondents, 49 were male (58.33\%) and 35 were female (41.67\%). The majority of the respondents were under 25 years old (48.81\%), followed by 27 respondents who were between 25 and 34 years old (32.14\%). 14 respondents (16.67\%) were 35 to 44 years old, and only 2 respondents $(2.38 \%)$ aged between 45 and 54 years old. There were no respondents older than 55 years old. Regarding the education level of participants, the sample predominantly consisted of graduate individuals, whilst only one respondent (1.19\%) was with primary and secondary school certification. 8 respondents (9.52\%) were with high school diploma, 63 respondents (75\%) were with graduate degrees, and 12 respondents (14.29\%) held post-graduate degrees. There were no participants with a doctorate degree.

The findings show that there is a significant positive correlation between consumer trust and e-loyalty with a significance scale of .686. These figures coincide with previous research findings such as Moreira and Silva (2015), Bart et al. (2005), and (Vos et al., 2014). In a similar fashion, the results show that there is a strong positive correlation between e-satisfaction and e-loyalty with a significance scale of .680. This means that the online consumers who were satisfied with the Kosovo e-tailers are willing to commit to repurchase intentions towards the e-tailers. These findings correspond with previous researchers' findings such as Chen (2012), Ludin and Cheng (2014), and (Ghane et al., 2011).

Although at a much lower significance, the correlation test results reveal that there is a slight positive correlation between website customisation based on cultural preferences such as language and layout and e-loyalty for the Kosovo e-tailers, with a significance scale of .270. The findings are on par with the suggestions of Cyr et al., (2008), and Zhang et al. (2011), although at a lower level. The respondents' relatively young age and fairly high level of education might explain the low significance of website customization to them.

\section{Conclusions and Future Research}

Retaining online consumers is integral for e-tail business success in Kosovo. Although e-tail marketing managers have been displaying lack of understanding on how to gain advantage and benefit from the extensive proportions of growth displayed recently in e-commerce, this approach has shown signs of change. Literature review indicates that doing business online is more complex and the market entry barriers are very low. Online consumers are exposed to innumerable competitive offers, and their switching cost constitutes only one mouse click.

E-loyalty is much more important for e-tailers compared to traditional retailers mainly because of the nature of the Internet environment. Apart from the fact that online consumers exhibit different behavioural patterns, they have shown indications of willingness to exhibit repurchase intentions. The findings of this research suggest that the majority of satisfied Kosovo online consumers intend to continue shopping from trustworthyKosovo online stores. The findings show that e-service quality, in the form of website customization based on local cultural preferences such as language and layout, plays a significant role in reaching consumer loyalty. However, the level of significance of this relationship is lower than trust and satisfaction.

For future research, replication longitudinal studies should be performed to gain better insight into this phenomenon. Additionally, more sophisticated sampling methods should be employed, in order to increase the validity and generalizability of the findings. The logical next step is to conduct future research on how to effectively build trust and satisfaction. The area of study can and should be extended in context to the moderating elements that impact this relationship. 


\section{References}

Amani, Z. (2015) Commitment as a Mediator of the relationship Between Trust and Relationship Loyalty to Retailer, Journal of Business Studies Quarterly, 6(3), 144-163

Al-hawari, M. A. (2015) How the Personality of Retail Bank Customers Interferes with the Relationship Between Service Quality and Loyalty, International Journal of Bank Marketing, 33(1), 41-57.

Al-Nasser, M., Yusoff, R.Z., Islam, R. and Al-Nasser, A. (2014) Relationship Among E-Service Quality, Culture, Attitude, Trust, Risk of Online Shopping, Journal of Social Scince, 10(3), 123-142

Asgari, N., Ahmadi, M. H., Shamlou, M., Farokhi, A. R. and Farzin, M. (2014) Studying the Impact of E-Service Quality on E-Loyalty of Customers in the Area of E-Banking Services, Journal of Management and Sustainability, 4(2), 126-133.

Babbie, E. (2015) The Practice of Social Research, 14th edition, Boston: Cengage Learning.

Bart, Y., Shankar, V., Sultan, F. and Urban, G. L. (2005) Are the Drivers and Role of Online Trust the Same for All Web Sites and Consumers? A Large-Scale Exploratory Empirical Study, Journal of Marketing, 69(4), 133-152.

Blumberg, B., Cooper, D. R. and Schindler, P. S. (2014) Business Research Methods, $4^{\text {th }}$ edition, Berkshire: McGraw-Hill Education.

Carter, M., Wright, R., Thatcher, J.B. and Klein, R. (2014) Understanding Online Customers' Ties to Merchants: The Moderating Influence of Trust on the Relationship Between Switching Costs and E-loyalty, European Journal of Information Systems, 23, 185-204. Available from: Doi:10.1057/ejis.2012.55 [Accessed $8^{\text {th }}$ May 2015].

Chen, S. (2012) The Customer Satisfaction-loyalty relation in an Interactive e-Service Setting: The Mediators, Journal of Retailing and Consumer Service, 19(2), 202-210.

Chen, C., O'Brien, M. and Guo, L. (2012) Consumer Trust and Loyalty in E-Tailing. In Close, A. G. Ed., (2012) Online Consumer Behaviour: Theory and Research in Social Media, Advertising, and E-Tail, New York: Routledge Taylor \& Francis Group.

Chen, C. and Saeedi, M. (2006) Building a Trust Model in the Online Market Place, Journal of Internet Commerce, 5(1), 101-115.

Cyr, D., Kindra, G. S. and Dash, S. (2008) Web Site Design, Trust, Satisfaction and E-Loyalty: The Indian Experience, Online Information Review, 32(6), 773-790.

DeLone, W. H. and McLean, E. R. (2004) Measuring e-Commerce Success: Applying the DeLone \& McLean Information Systems Success Model, International Journal of Electronic Commerce, 9(1), 31-47.

Deng, Z., Lu, Y., Wei, K. K. and Zhang, J. (2010) Understanding Customer Satisfaction and Loyalty: An empirical Study of Mobile Instant Messages in China, International Journal of Information Management, 30(4), 289-300.

Elkhani, N., Soltani, S. and Jamshidi, M. H. M. (2014) Examining a Hybrid Model for e-Satisfaction and E-Loyalty to E-Ticketing on Airline Website, Journal of Air Transport Management, 37, 46-44. Available from: Doi:10.1016/j.jairtraman.2014.01.006 [Accessed 1st of May 2015].

Fang, Y., Qureshi, I., Sun, H., McCole, P., Ramsey, E. and Lim, K. H. (2014) Trust, Satisfaction, and Online Repurchase Intention: The Moderating Role of Perceived Effectiveness of E-Commerce Institutional Mechanisms, MIS Quarterly, 38(2), 402-427.

Fisher, C. (2010) Researching and Writing a Dissertation: An Essential Guide for Business Students, 3rd Edition, Harlow: Pearson Education Limited.

Flint, D.J., Blocker, C. P. and Boutin, Jr. P. J. (2011) Customer Value Anticipation, Customer Satisfaction and Loyalty: An Empirical Examination, Industrial Marketing Management, 40(2), 2019-230.

Ghane, S., Fathian, M. and Gholamian, M. R. (2011) Full Relationship Among E-Satisfaction, E-Trust, E-Service Quality, and E-Loyalty: The Case of Iran E-Banking, Journal of Theoretical and Applied Information Technology, 33(1), 1-6.

Gounaris, S.m Dimitriadis, S. and Stathakopoulas, V. (2010) An Examination of the Effects of Service Quality and Satisfaction on Consumers' Behavioural Intention in E-Shopping, Journal of Services Marketing, 24(2), 142-156.

Han, H. and Woods, D. P. (2014) Attitudinal and Behavioural Aspects of Loyalty in the Screen-Golf Industry, Journal of Quality Assurance in Hospitality \& Tourism, 15(2), 175-189.

Harris, L. C. and Goode, M. H. (2004) The Four Levels of Loyalty and Pivotal Role of Trust: a Study of Online Service Dynamics, Journal of Retailing, 80(2), 139-158.

Hsieh, M. \& Tsao, W. (2014) Reducing Perceived Online Shopping Risk to Enhance Loyalty: A Website Quality Perspective, Journal of Risk Management, 17(2), 241-261.

Hurwitz, J. G. (2013) Trust and Online Interaction, University of Pennsylvania Law Review, 161, 1579-1622. Available from: http://scholarship.law.upenn.edu/penn_law_review/vol161/iss6/4. [Accessed 12 April 2015].

Jumaev, M., Kumar, D. M. and Hanaysha, J. R. M. (2012) Impact of Relationship Marketing on Customer Loyalty in the Banking Sector, Far East Journal of Psychology and Business, 6(3), 36-55.

Kim, J., Jin, B. and Swinney, J. L. (2009) The Role of Etail Quality, e-Satisfaction and e-Trust in Online Loyalty Development Process, Journal of Retailing and Consumer Services, 16(4), 239-247.

Kosovo Agency of Statistics (2013) Facts about Population: ASK, [Online]. Available from http://ask.rks-gov.net/ENG/home [Accessed 17th April 2015].

Kosovo Ministry of Foreign Affairs (2015) Kosovo Connectivity at Global Standards on Internet Usage. Available from http://www.mfaks.net/?page=2,4,1944 [Accessed 11 April 2015]. 